\title{
Combination treatment of malignant $B$ cells using the anti-CD20 antibody rituximab and the anti-malarial artesunate
}

\author{
SEBASTIAN SIEBER ${ }^{1}$, GEORG GDYNIA ${ }^{2}$, WILFRIED ROTH ${ }^{2}$, BENJAMIN BONAVIDA ${ }^{3}$ and THOMAS EFFERTH ${ }^{1}$ \\ ${ }^{1}$ German Cancer Research Center, Pharmaceutical Biology (C015), ${ }^{2}$ German Cancer Research Center, Molecular Neuro- \\ Oncology (G150), D-69120 Heidelberg, Germany; ${ }^{3}$ University of California in Los Angeles, School of Medicine, \\ Department of Microbiology, Immunology and Molecular Genetics, Los Angeles, CA, USA
}

Received September 5, 2008; Accepted December 8, 2008

DOI: 10.3892/ijo_00000323

\begin{abstract}
Chemotherapy of non-Hodgkin's lymphoma is frequently hampered by drug resistance. The monoclonal antibody rituximab specifically targets the CD20 antigen and sensitizes B-cell lymphoma cells to standard anticancer drugs. In the present investigation, we analyzed, whether a combination of rituximab and artesunate may act in a complementary manner and eventually synergize in tumor cell killing. Artesunate is an anti-malarial drug, which also exerts profound activity towards cancer cells. While rituximab alone was minimally cytotoxic, rituximab increased cytotoxicity to artesunate in Ramos cells. Artesunate induced apoptosis, induced Fas/CD95 expression and the formation of reactive oxygen species (ROS) and resulted in a breakdown of mitochondrial membrane potential. This argues for the involvement of both receptor-driven extrinsic and mitochondrial intrinsic routes of apoptosis. Rituximab increased Fas/CD95 expression and ROS formation and decreased mitochondrial membrane potential ultimately leading to increased apoptosis induced by artesunate. The transcription factors YY1 and Sp1 are upstream regulators of apoptosis by controlling the expression of apoptosis-regulating genes. YY1 and Sp1 were down-regulated and Fas/CD95 was upregulated by rituximab and artesunate indicating that artesunate activated the Fas/CD95 pathway and that rituximab increased the susceptibility of tumor cells to artesunateinduced apoptosis. Furthermore, rituximab affected the expression of antioxidant genes. The antibody decreased artesunate-induced up-regulation of catalase expression and increased artesunate-induced down-regulation of glutathione S-transferase- $\pi$ expression. Manganese-dependent superoxide
\end{abstract}

Correspondence to: Professor Thomas Efferth, German Cancer Research Center, Pharmaceutical Biology (C015), Im Neuenheimer Feld 280, D-69120 Heidelberg, Germany

E-mail: t.efferth@dkfz.de

Key words: Artemisia annua, cancer, chemotherapy, immune therapy, natural products, pharmacognosy, traditional Chinese medicine dismutase expression was not changed by artesunate. Antioxidant proteins may help to detoxify artesunate-induced ROS. Rituximab reversed the artesunate-induced expression changes of antioxidant genes and, hence, reduced the detoxification capacity of Ramos cells. The effects of rituximab on antioxidant genes represent a novel mechanism of rituximab for chemosensitization.

\section{Introduction}

Non-Hodgkin's lymphoma (NHL) represents a heterogeneous tumor entity of the immune system. A typical feature is monoclonal expansion of both B- and T-lymphocytes. The incidence of NHL is rising, and NHL ranks the fifth in cancer mortality. In the United States, over 60,000 new NHL cases with a mortality rate of approximately 20,000 cases are estimated for 2007 (1). Chemotherapy of NHL is frequently hampered by the development of tumor drug resistance and severe side effects to normal tissues. A significant change in the treatment options has occurred since the advent of monoclonal antibody $(\mathrm{mAB})$ treatment. MAbs are more specific than established chemotherapy by targeting defined cell surface markers and are less toxic to normal tissues.

The mAb rituximab specifically targets the CD20 antigen on B cells (2). It is used for the treatment of NHL and other B-cell malignancies $(3,4)$. Though CD20 is also expressed on normal B cells, rituximab does not reveal severe toxicity (2). Previous studies have shown that rituximab sensitizes B cell lymphoma cells to cell killing by standard anticancer drugs (5) and reverses drug resistance of NHL cells (6). Rituximab inhibits p38 mitogen-activated protein kinase (MAPK), nuclear factor- $\mathrm{B}(\mathrm{NF}-\kappa \mathrm{B})$, extracellular signal-regulated kinase 1/2 (ERK1/2), and AKT anti-apoptotic survival pathways. As a result, the antiapoptotic regulators Bcl-2, Bcl- $\mathrm{X}_{\mathrm{L}}$, and $\mathrm{Mcl}-1$ are down-regulated, which leads to sensitization of tumor cells towards cytostatic drugs (7). The selective suppression of antiapoptotic proteins is regulated by the intrinsic mitochondrial pathway $(8,9)$. Recent reports also discuss a role of rituximab for the inhibition of the transcription repressor Yin-Yang 1 (YY1) leading to upregulation of Fas expression and sensitization to Fas agonistinduced apoptosis $(10,11)$.

Many medicinal plants have pharmacological activities and may, thus, be a source for novel treatment strategies. 
We have systematically analyzed medicinal plants used in traditional Chinese medicine during the past decade and focused our interest on Artemisia annua L. (qinhao, sweet wormwood). We found that the active principle of Artemisia аппиа L., artemisinin, and its derivative artesunate, exert not only anti-malarial activity but also profound cytotoxicity against tumor cells (12-17). Candidate genes that contribute to the sensitivity and resistance of tumor cells to artemisinins were identified by pharmacogenomic and molecular pharmacological approaches $(18,19)$. Target validation was performed using cell lines transfected with candidate genes or corresponding knockout cells. These genes are from classes with different biological function; for example, regulation of proliferation ( $B U B 3$, cyclins, $C D C 25 A)$, angiogenesis (vascular endothelial growth factor and its receptor, matrix metalloproteinase-9, angiostatin, thrombospondin-1) or apoptosis $(B C L-2, B A X)(13,19,20)$. Artesunate triggers apoptosis both by p53-dependent and -independent pathways (19). Antioxidant stress genes (thioredoxin, catalase, $\gamma$ glutamyl-cysteine synthetase, glutathione S-transferases) as well as the epidermal growth factor receptor confer resistance to artesunate $(19,21)$. Cell lines overexpressing genes that confer resistance to established antitumor drugs (MDR1, MRP1, BCRP, dihydrofolate reductase, ribonucleotide reductase) were not cross-resistant to artesunate, indicating that artesunate is not involved in multidrug resistance $(13,22)$. The anticancer activity of artesunate has also been shown in human xenograft tumors in mice (23). First experiences in the clinical treatment of patients suffering from uveal melanoma were encouraging (24).

Here, we addressed the question, whether a combination of rituximab and artesunate may act in a complementary manner and eventually synergize in tumor cell killing. A central question regarding the phenomenon of drug sensitization by rituximab involves the role that drugs play in the generation of reactive oxygen species (ROS) finally leading to apoptosis. The aim of the present investigation was, therefore, to investigate the mechanisms by which rituximab sensitizes NHL to artesunate-induced apoptosis and the role that artesunate plays in the initiation of apoptosis. We hypothesize that both agents act synergistically by activating at least partially converging signaling pathways.

\section{Materials and methods}

Cell culture and reagents. The human lymphoma B cell line Ramos was purchased from the American Type Culture Collection. The tumor cell line was maintained with RPMI-1640 (Mediatech, Manassas, VA, USA), 10\% heatinactivated fetal calf serum and $1 \%$ penicillin/streptomycin (both Invitrogen, Karlsruhe, Germany) under standard conditions $\left(37^{\circ} \mathrm{C}, 5 \% \mathrm{CO}_{2}\right)$ as described previously $(25,26)$. Ramos cells have been shown to express CD20 (27).

Artesunate (ART) was purchased from Saokim Ltd. (Hanoi, Vietnam). Cisplatin (CDDP) was obtained from Sigma (Munic, Germany). Dimethylsulfoxide (DMSO; Sigma) was used to dissolve and prepare stock solutions of ART $(20 \mathrm{mg} / \mathrm{ml})$ and CDDP $(20 \mathrm{mg} / \mathrm{ml})$. The XTT cytotoxicity assay kit was purchased from Roche Diagnostics (Mannheim, Germany).
Treatment with rituximab and artesunate. Rituximab antibody was kindly provided by Dr Christos Emmanouilides (Department of Medicine, UCLA School of Medicine, Los Angeles, CA, USA) and PD Dr Manfred Hensel (Department of Pediatrics, University of Heidelberg, Germany). Ramos cells $\left(5 \times 10^{5}\right.$ cells $\left./ \mathrm{ml}\right)$ were either left untreated (control) or were treated with concentrations of $0-30 \mu \mathrm{g} / \mathrm{ml}$ of rituximab or artesunate $(0-100 \mu \mathrm{M})$ and incubated for indicated timepoints at $37^{\circ} \mathrm{C}$ and $5 \% \mathrm{CO}_{2}$. For combination treatment, cells were pre-incubated with rituximab $(20 \mu \mathrm{g} / \mathrm{ml}, 24 \mathrm{~h})$ followed by artesunate $(0-100 \mu \mathrm{M}, 24 \mathrm{~h})$ treatment. As a control, cells were incubated with DMSO (equal volume of artesunate). At the end of the incubation period, cells were harvested and washed once with ice-cold $1 \mathrm{X}$ PBS/0.1\% BSA.

XTT assay. The toxicity of compounds was determined by means of the Cell Proliferation Kit II (Roche Diagnostics). This test is based on the cleavage of the yellow tetrazolium salt XTT by ubiquitous dehydrogenases leading to the formation of an orange formazan dye. The amount of dye is commensurate to the number of metabolic active cells. Stock solutions of each compound were prepared in DMSO with a concentration of $20 \mathrm{mg} / \mathrm{ml}$. Before use, these stock solutions were diluted using medium to the concentrations needed for testing. Cells were diluted to a final concentration of $1 \times 10^{5}$ cells $/ \mathrm{ml}$. One hundred microliters of the cell suspension was placed into the wells of a 96-well culture plate (Costar, Corning, USA). Marginal wells were filled with $100 \mu \mathrm{l}$ of pure medium in order to minimize effects of evaporation. Additionally, wells filled with medium were used to determine the background absorbance caused by non-metabolized XTT. Three cell containing wells were left untreated. The other cell containing wells were supplemented with different concentrations of compound. Each concentration was tested in three wells per plate with at least two independent plates containing different batches of cells.

After incubation with drugs at $37^{\circ} \mathrm{C}, 5 \% \mathrm{CO}_{2}$ in humidified atmosphere, XTT was added as specified by the manufacturer: XTT-labeling reagent and electron-coupling reagent were mingled in a ratio of 50:1 and $50 \mu 1$ of this mixture was added to each well of the 96-well plate. The plates were incubated for $18 \mathrm{~h}$ at $37^{\circ} \mathrm{C}, 5 \% \mathrm{CO}_{2}$ in humidified atmosphere and read out after incubation. Quantification of cell cytotoxicity was performed in an ELISA plate reader (Bio-Rad, Munic, Germany) at $490 \mathrm{~nm}$ with a reference wavelength of $655 \mathrm{~nm}$. Absorbance values at both wavelengths were subtracted. The cytotoxic effect of the treatment was determined as percentage of viability compared to untreated cells.

$$
\text { Cell viability }(\%)=\frac{\text { Absorbance of sample cells }}{\text { Absorbance of untreated cells }} \times 100
$$

Flow cytometry. Following analysis was performed on a FACSCalibur flow cytometer (Becton-Dickinson, Heidelberg, Germany) using the software CellQuestPro (BectonDickinson). For each sample 10,000-15,000 cells were counted according to the respective experiment. Single cells were gated to exclude doublets from measurement. 
Analysis of apoptosis by staining with propidium iodide. Cells were stained with propidium iodide (PI, Sigma, Münic, Germany) according to a previously described protocol (28). After treatment of cells with artesunate, rituximab, or combinations of artesunate and rituximab, cells were collected and washed in PBS/0.1\% BSA. Subsequently, cells were permeabilized by re-suspension in $500 \mu \mathrm{l}$ of cold $75 \%$ ethanol and incubated at $-20^{\circ} \mathrm{C}$ for $1 \mathrm{~h}$. Then, cells were washed twice in PBS/0.1\% BSA and re-suspended in $100 \mu 1$ PI staining solution $(100 \mu \mathrm{g} / \mathrm{ml} \mathrm{PI}, 0.1 \%$ sodium citrate, $0.1 \%$ Triton, and $50 \mu \mathrm{g} / \mathrm{ml}$ RNAse). Cells were incubated for $30 \mathrm{~min}$ at $37^{\circ} \mathrm{C}$ in the dark. After PI staining, $300 \mu 1 \mathrm{PBS}$ was added to each sample. The samples were transferred to FACS tubes on ice and then analyzed using a FACSCalibur flow cytometer (FL1).

Analysis of reactive oxygen species (ROS). Cells were harvested and transferred to Eppendorf vials protected by light by aluminium foil. One microliter of $2^{\prime}, 7^{\prime}$-dichlorodihydrofluorescein diacetate (DCFH-DA; Sigma) stock solution (10 $\mathrm{mM}$ in DMSO) was added to each sample. DCFH-DA is a ROS-sensitive compound, whose degradation by intracellular peroxides results in the generation of a fluorescent breakdown by-product. Samples were vortexed immediately and incubated for $30 \mathrm{~min}$ at $37^{\circ} \mathrm{C}, 5 \% \mathrm{CO}_{2}$ in a humidified atmosphere. Subsequent steps were performed on ice. Cells were washed twice with PBS, re-suspended in $500 \mu 1 \mathrm{PBS}$, transferred to FACS tubes and analyzed by flow cytometry (FL1).

Analysis of mitochondrial membrane potential. Cells were harvested and transferred into Eppendorf vials protected from light by aluminum foil. One microliter of 3,3'-dihexyloxacarbocyanine iodide $(40 \mu \mathrm{mol} / \mathrm{ml})$ (Molecular Probes, Inc., Eugene, USA) was added to each sample. Samples were incubated for $30 \mathrm{~min}$ at $37^{\circ} \mathrm{C}\left(5 \% \mathrm{CO}_{2}\right.$, humidified atmosphere). Subsequent steps were performed on ice. Cells were washed twice with PBS, re-suspended in $500 \mu 1 \mathrm{PBS}$, transferred to FACS tubes (Fisher, USA) and analyzed using a FACSCalibur flow cytometer (FL1). For each sample 15,000 cells were counted.

Determination of surface Fas/CD95 expression. For Fas/ CD95 analysis, cells were collected and resuspended in $50 \mu 1$ PBS containing $250 \mathrm{ng} / \mathrm{ml}$ of anti-Fas (CD95/apo-1) and $10 \mathrm{ng} / \mathrm{ml}$ Protein A and incubated for $15 \mathrm{~min}$ at $4^{\circ} \mathrm{C}$. The monoclonal antibody FAS (CD95/Apo-1) and Protein A were kindly provided by Dr Min Li-Weber, DKFZ, Heidelberg, Germany. The cells were then washed and incubated with a 1:200 dilution of goat anti-mouse antibody PE-conjugated (provided by Dr Min Li-Weber, DKFZ, Heidelberg, Germany or Jackson Immuno Research Europe, Suffolk, UK) in PBS at $4^{\circ} \mathrm{C}$ for further $15 \mathrm{~min}$. Cells were washed once in PBS, resuspended in $300 \mu \mathrm{l}$ PBS and analyzed by flow cytometry with an FACSCalibur flow cytometer (FL2). Fifteen thousand cells were counted for each sample.

Western blot analysis. Ramos cells $\left(10^{6}\right)$ were seeded in 6or 12-well plates (Costar) and were either left untreated (control) or were treated with varying concentrations of artesunate $(25,50$ and $100 \mu \mathrm{M}, 24 \mathrm{~h})$. For combination treatment cells were preincubated with rituximab $(20 \mu \mathrm{g} / \mathrm{ml}$, $24 \mathrm{~h})$ followed by artesunate treatment $(0,25,50$ and $100 \mu \mathrm{M}$, $24 \mathrm{~h})$. Then cells were collected, washed once with PBS and lysed in cold radioimmunoprecipitation assay buffer (RIPA) [50 mM Tris $\mathrm{HCl}, \mathrm{pH} 7.4 ; 150 \mathrm{mM} \mathrm{NaCl} ; 1 \mathrm{mM}$ phenylmethylsulfonylfluoride; $1 \mathrm{mM}$ EDTA; $1 \%$ (v/v) Triton X$100 ; 1 \%(\mathrm{w} / \mathrm{v})$ sodium deoxycholate; $0.1 \%(\mathrm{w} / \mathrm{v})$ SDS and 1X PBS] supplemented with protease inhibitor cocktail tablets (Boehringer, Mannheim, Germany).

After $15 \mathrm{~min}$ incubation on ice, the lysates were centrifuged at $13.000 \mathrm{rpm}$ at $4^{\circ} \mathrm{C}$ for $20 \mathrm{~min}$. Lysate supernatants were quantified for protein concentration using the Bio-Rad DC protein assay (Bio-Rad). A volume of 1:6 of sample buffer [375 mM Tris/HCl, pH 6.8; $19 \%$ (v/v) glycerol; $2 \%$ $(\mathrm{w} / \mathrm{v})$ SDS, 6\% (v/v) ß-mercaptoethanol; $5.4 \mathrm{mM}$ bromophenol blue] was then added to the supernatant and boiled for $5 \mathrm{~min}$. The cell lysates $(40-50 \mu \mathrm{g})$ were then subjected to gel electrophoresis and were transferred to Trans-Blot nitrocellulose membranes (Bio-Rad). After blocking for $1 \mathrm{~h}$ with $5 \%$ skim-milk in tris-buffered saline/0.1\% Tween-20 (TBS/T), the membranes were incubated overnight at $4{ }^{\circ} \mathrm{C}$ with primary antibodies [catalase (CAT), manganese-dependent superoxide dismutase (MnSOD), glutathione S-transferase- $\pi$ (GSTP), Yin-Yang 1 (YY1), ß-actin, ß-tubulin (all 1:3000) and specificity protein $(\mathrm{Sp} 1 ; 1: 300)]$. The membranes were washed three times in TBS/T, incubated for $1 \mathrm{~h}$ with horseraddish peroxidase conjugated secondary anti-mouse or antirabbit antibody at room temperature and then washed again. Nitrocellulose blots were developed using the enhanced chemiluminescence detection system (ECL) followed by exposure to ECL-Hyperfilm (Amersham Buchler, Braunschweig, Germany).

The monoclonal antibody against $\mathrm{Sp} 1$ was purchased from BD Biosciences Pharmingen (Heidelberg, Germany). Antibodies against $\beta$-actin and $\beta$-tubulin were purchased from Chemicon (Hampshire, UK) and Cellsignal (Danvers, USA), respectively. The antibody used for detection of YY1 was obtained from Santa Cruz (Heidelberg, Germany). The polyclonal antibody against CAT was purchased from Biomol (Hamburg, Germany), and polyclonal antibodies against MnSOD and GSTP were from Upstate (Lake Placid, USA) and Stressgen (Victoria, Canada), respectively. Secondary anti-mouse and anti-rabbit antibodies were purchased from Santa Cruz and Bio-Rad.

The relative density of the bands was determined by densitometric analysis using ImageQuant TL (Amersham Biosciences, Piscataway, NJ, USA). A ratio of band/band actin was formed for each lane and referred to the ratio of the untreated sample.

Determination of caspase- 3 activity. Tumor cells $\left(5 \times 10^{5}\right)$ were seeded in a 12-well plate and incubated either with artesunate $(200 \mu \mathrm{M}, 6 \mathrm{~h})$ or rituximab $(20 \mu \mathrm{g} / \mathrm{ml}, 6 \mathrm{~h})$ alone or were pre-incubated with rituximab $(20 \mu \mathrm{g} / \mathrm{ml}, 1 \mathrm{~h})$, followed by artesunate $(200 \mu \mathrm{M}, 6 \mathrm{~h})$ treatment. As a control, cells were incubated with DMSO (equal volume of artesunate) or rituximab and DMSO, respectively. The cells were then harvested, washed with PBS and lysed in RIPA buffer in the absence of protease inhibitors. Subsequently, lysates were centrifuged at $13.000 \mathrm{rpm}$ at $4^{\circ} \mathrm{C}$ for $20 \mathrm{~min}$ and the super- 

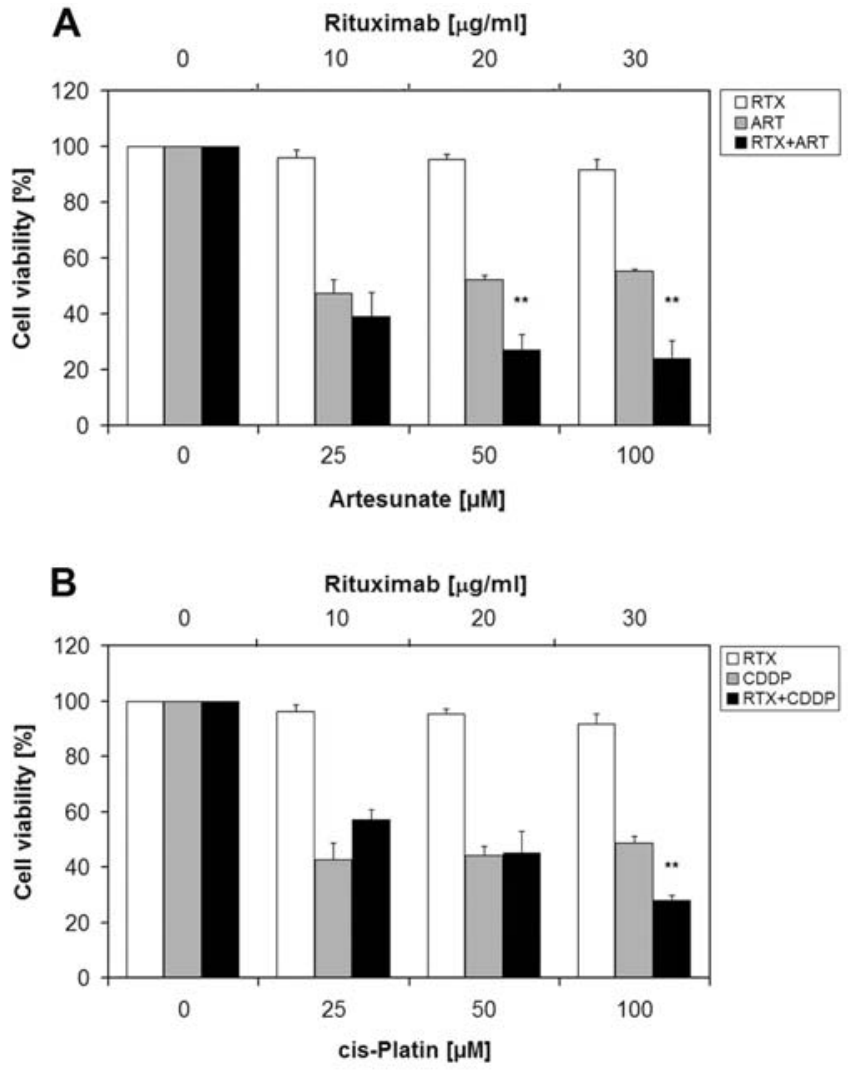

Figure 1. Rituximab potentiates the cytotoxic effect of artesunate in nonHodgkin's lymphoma cells. (A) Ramos cells were treated with rituximab (0$30 \mu \mathrm{g} / \mathrm{ml}, 24 \mathrm{~h})$, artesunate $(0-100 \mu \mathrm{M}, 24 \mathrm{~h})$ or combinations of both. For this purpose, cells were preincubated with rituximab $(20 \mu \mathrm{g} / \mathrm{ml}, 24 \mathrm{~h})$ followed by addition of artesunate $(0-100 \mu \mathrm{M})$ for further $24 \mathrm{~h}$. Control samples were allowed to grow without treatment. Cytotoxicity was assessed by the XTT assay. The enhancement of cytotoxicity in rituximab and artesunate combinations was statistically significant when compared with treatment with rituximab or artesunate alone. Mean and standard error mean (SEM) of three independent experiments (each with triplicates) are shown. ${ }^{* *} \mathrm{P} \leq 0.01$. (B) Ramos cells were treated with $0-30 \mu \mathrm{g} / \mathrm{ml}$ rituximab, 0-100 $\mu \mathrm{M}$ cisplatin or combinations of both for $24 \mathrm{~h}$. For details see (A).

natant was transferred to fresh vials. Activity of caspase-3 was determined by using the fluorogenic tetrapeptide AcDEVD-AFC (Axxora, Lörrach, Germany) as synthetic substrate of caspase-3. Reaction buffer [50 mM HEPES, $50 \mathrm{mM} \mathrm{NaCl}, 0.1 \%(\mathrm{w} / \mathrm{v})$ Chaps, $10 \mathrm{mM}$ EDTA, 5\% (v/v) glycerol, $10 \mathrm{mM}$ 1,4-dithio-DL-threitol] containing $50 \mu \mathrm{M}$ of substrate was then added to equal amounts of protein and incubated at $37^{\circ} \mathrm{C}$ for $20 \mathrm{~min}$ in the dark. Caspase- 3 activity was assayed by a fluorescence microplate reader at a wavelength of $495 \mathrm{~nm}$.

Statistical analysis. The results are expressed as the mean \pm SD. Statistical analysis between groups was performed using Student's t-test. Results were considered to be significant when $\mathrm{P}<0.05$.

\section{Results}

Potentiation of artesunate cytotoxicity by rituximab. To determine the feasibility of rituximab artesunate combinations for the treatment of non-Hodgkin's lymphoma, we sought to establish whether rituximab potentiates the cytotoxicity of artesunate. Ramos cells were treated with rituximab (0-30 $\mu \mathrm{g}$ / $\mathrm{ml}, 24 \mathrm{~h})$, artesunate $(0-100 \mu \mathrm{M}, 24 \mathrm{~h})$ or combinations of both. As shown in Fig. 1A, rituximab significantly potentiated the cytotoxicity of artesunate $(\mathrm{P} \leq 0.01)$. Rituximab alone did only minimally exert cytotoxic effects, whereas artesunate was cytotoxic even in low concentrations. In combination treatments, rituximab significantly potentiated the cytotoxicity of artesunate $(\mathrm{P} \leq 0.01)$. A comparable experiment has been performed with rituximab cisplatin combinations. Since rituximab is known to synergize the cytotoxic effects of cisplatin (6), this experiment served as a control. As expected, we found that rituximab also potentiated the effects of cisplatin (Fig. 1B).

Effect of rituximab on artesunate-induced apoptosis. In order to analyze, whether the synergistic effect of both agents is due to apoptosis, we applied flow cytometry and the Nicoletti assay. Ramos cells were treated with rituximab alone or with a combination of rituximab and artesunate. Apoptosis was assessed by PI staining (Fig. 2). Rituximab (20 $\mu \mathrm{g} / \mathrm{ml})$ had no considerable effect on apoptosis compared to untreated cells and DMSO mock control (Fig. 2B, A and E). Artesunate $(50 \mu \mathrm{M})$ induced apoptosis in $36.1 \%$ of cells (Fig. 2C). When Ramos cells were treated with both rituximab and artesunate, the fraction of apoptotic cells increased to $42.1 \%$ (Fig. 2D). The potentiation of apoptosis by the combination treatment compared to each compound alone was found in three experiments and was statistically significant at a concentration of $50 \mu \mathrm{M}$ artesunate and $20 \mu \mathrm{g} /$ $\mathrm{ml}$ rituximab $(\mathrm{P}=0.0055$; Fig. $2 \mathrm{~F})$.

Effect of rituximab on artesunate induced FAS expression, generation of reactive oxygen species, and changes in mitochondrial membrane potential. Cytotoxic drugs are known to induce apoptosis by activation of the CD95 pathway (29). Therefore, we measured Fas/CD95 protein levels by a phycoerythrin (PE)-labeled monoclonal antibody directed against anti-Fas/CD95 primary antibody (goat anti-mouse, IgG-PEA) and flow cytometry in Ramos cells to determine whether the induction of apoptosis in rituximab and artesunate treated cells was due to regulation of Fas/CD95 expression (Fig. 3A). Rituximab alone had only a minimal effect on Fas/CD95 expression compared to untreated control cells. In contrast, artesunate substantially increased Fas/CD95 expression, which was further increased by a combination of rituximab and artesunate.

Next, we analyzed whether the induction of apoptosis and Fas/CD95 expression was associated with the generation of reactive oxygen species (ROS) (Fig. 3B). Treatment of Ramos cells with rituximab or artesunate alone increased the amount of ROS. The highest levels of ROS were observed after a combination treatment of rituximab and artesunate.

ROS generated by anticancer agents are known to disrupt mitochondrial integrity as an initializing event for induction of apoptosis (30). $\mathrm{DiOC}_{6}$ staining was applied to investigate, whether rituximab and artesunate interfered with mitochondrial membrane stability. As shown in Fig. 3C, rituximab alone was not sufficient to change mitochondrial membrane potential, 

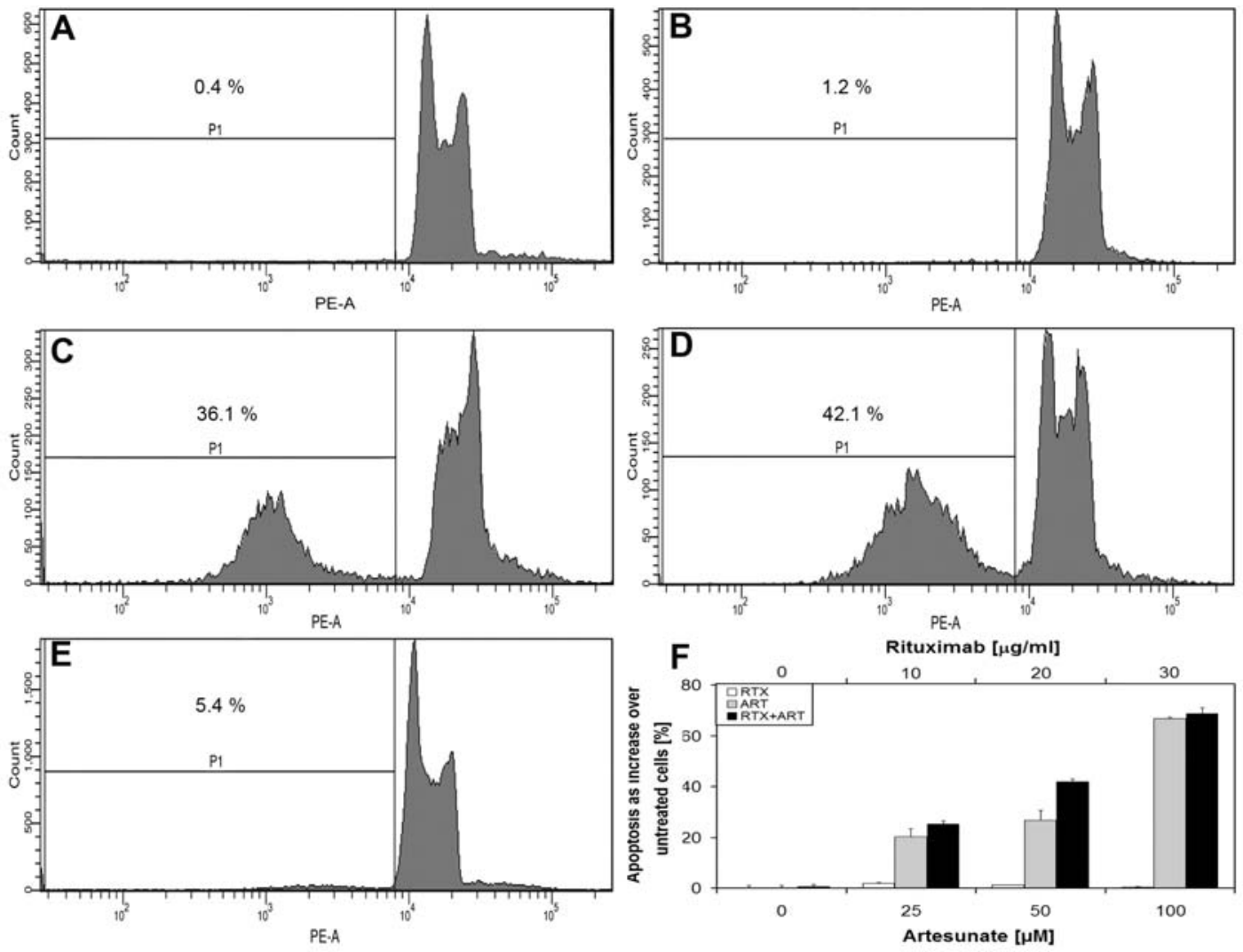

Figure 2. Ramos cells undergo apoptosis when treated with rituximab and artesunate. Apoptosis was measured by PI-staining and flow cytometry. (A), Untreated control; (B), rituximab alone (20 $\mu \mathrm{g} / \mathrm{ml})$; (C), artesunate alone $(50 \mu \mathrm{M}) ;(\mathrm{D})$, combination of rituximab $(20 \mu \mathrm{g} / \mathrm{ml})$ and artesunate (50 $\mu \mathrm{M})$; (E), DMSO control; (F), mean values and standard deviations of three experiments. Artesunate at a concentration of $50 \mu \mathrm{M}$ showed the strongest potentiation in combination with rituximab $(20 \mu \mathrm{g} / \mathrm{ml})(\mathrm{P}=0.0055)$.
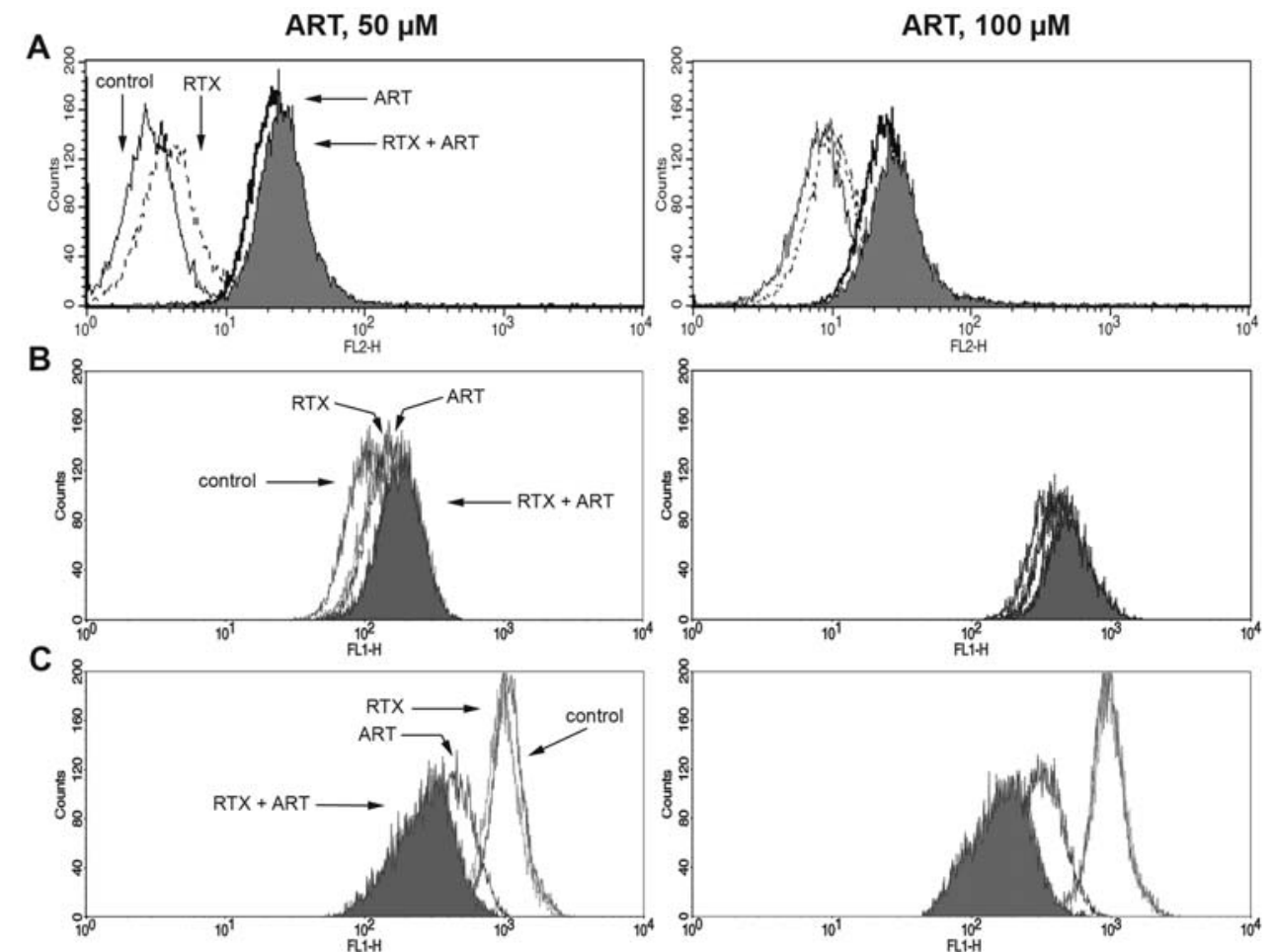

Figure 3. Rituximab potentiates the effects of artesunate. (A) Fas/CD95 expression. Cells were treated with rituximab $(20 \mu \mathrm{g} / \mathrm{ml}, 48 \mathrm{~h})$, artesunate (50, $100 \mu \mathrm{M}$; $48 \mathrm{~h}$ ) or a combination of both. For this purpose, Ramos cells were pre-incubated with rituximab ( $3 \mathrm{~h}$ ) followed by artesunate treatment for $48 \mathrm{~h}$. (B) Generation of ROS. Cells were incubated with rituximab $(20 \mu \mathrm{g} / \mathrm{ml})$ or artesunate $(50,100 \mu \mathrm{M})$ for $6 \mathrm{~h}$. For combination therapy, cells were pre-incubated with rituximab $(3 \mathrm{~h})$ and treated with artesunate $(6 \mathrm{~h}) .(\mathrm{C})$ Depolarization of mitochondrial membrane potential. For details see (A). Measurements were done by means of flow cytometry and (A) PE-labeled monoclonal antibody (goat anti-mouse) directed against anti-Fas/CD95 primary antibody (B) DCFH-DA staining and $(\mathrm{C}) \mathrm{DiOC}_{6}$ staining. Representative histograms of each three independent experiments are shown. 


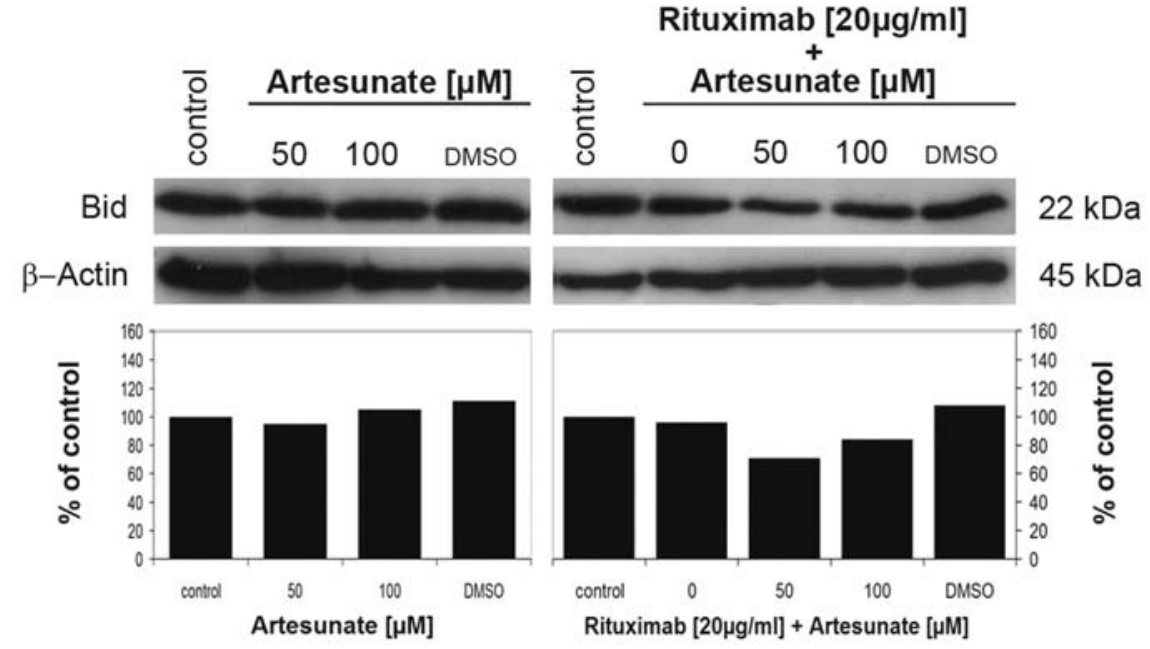

Figure 4. Rituximab and artesunate do not affect Bid expression. Ramos cells were treated for $24 \mathrm{~h}$ with rituximab (20 $\mu \mathrm{g} / \mathrm{ml})$, artesunate ( 25,50 and $100 \mu \mathrm{M}$, $24 \mathrm{~h}$ ) or a combination of both agents.

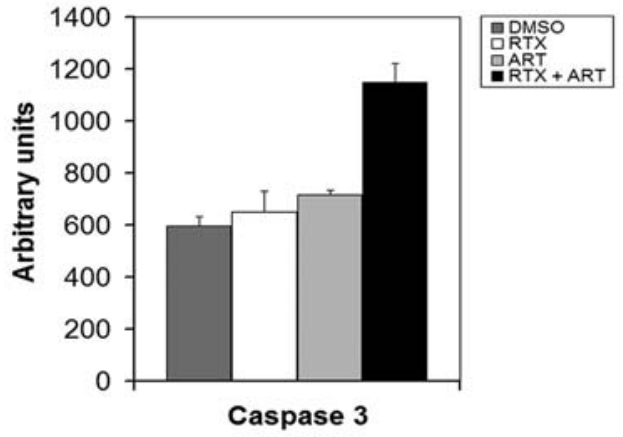

Figure 5. Rituximab and artesunate activate caspase-3 in Ramos cells when added in combination but only minimally when added alone. Ramos cells were treated for $6 \mathrm{~h}$ with rituximab $(20 \mu \mathrm{g} / \mathrm{ml})$, artesunate $(200 \mu \mathrm{M})$ or a combination of both agents (pre-incubation with $20 \mu \mathrm{g} / \mathrm{ml}$ rituximab for $1 \mathrm{~h}$ followed by addition of artesunate for further $6 \mathrm{~h}$ ). ${ }^{* * *} \mathrm{P}=0.0006$.

whereas artesunate alone induced a considerable left shift indicating a breakdown of mitochondrial membrane potential. The combination of rituximab and artesunate caused a further decrease of the mitochondrial membrane potential.

Effect of rituximab and artesunate on Bid expression. Bid is a $\mathrm{Bcl}-2$ family member which is activated during apoptosis and translocated to the mitochondrial membrane. Therefore, we investigated the role of Bid for the synergy of artesunate and rituximab. As shown in Fig. 4, artesunate and rituximab alone or in combination did not or only minimally affect Bid protein expression.

Caspase-3 activation. As mitochondrial depolarization during apoptosis is associated with caspase activation, we analyzed caspase-3 after exposure to rituximab and artesunate. Both agents alone did only minimally activate caspase-3 (Fig. 5). When treated with both agents in combination, a significant increase of caspase- 3 activation was observed in Ramos cells $(\mathrm{P}=0.0006)$.
Inhibition of transcription factors. Transcription factors are involved in apoptosis by regulating the expression of apoptosis-driving genes. YY1 has been reported to negatively regulate FAS expression and YY1 inhibition up-regulates FAS expression leading to FAS-induced apoptosis (31). Therefore, we examined whether rituximab- and artesunateinduced up-regulation of FAS expression might be regulated by YY1. Treatment of Ramos cells with artesunate alone (Fig. 6, upper left panel) or rituximab alone (Fig. 6 upper right panel, lane 2) resulted in inhibition of YY1 expression. The combination of artesunate and rituximab leads to an increased inhibition of YY1 expression (Fig. 6, upper right panel).

To investigate whether the transcription factor Sp1 might also be involved in the synergy of rituximab and artesunate, we analyzed Ramos cells treated with both agents alone or in combination for their $\mathrm{Sp} 1$ expression. Artesunate treatment of Ramos cells caused a down-regulation of $\mathrm{Sp} 1$ expression, an effect which was further enhanced by rituximab (Fig. 6, lower left and right panels).

Effect of rituximab and artesunate on antioxidant proteins. Since artesunate produced ROS in Ramos cells (Fig. 3B), we investigated the influence of artesunate and rituximab on the expression of antioxidant proteins. Artesunate treatment of Ramos cells caused a dose-dependent increase of catalase (CAT) expression (Fig. 7, upper left panel). Treatment with rituximab alone did not change CAT expression. Interestingly, the up-regulation of CAT observed with artesunate alone was reduced by rituximab in the combination treatment (Fig. 7 , upper right panel).

Artesunate alone had no effect on the expression of manganese-dependent superoxide dismutase (MnSOD). Rituximab alone and in combination with artesunate reduced MnSOD protein expression (Fig. 7, middle panels).

Treatment of Ramos cells with artesunate alone resulted in a dose-dependent down-regulation of glutathione Stransferase- $\pi$ (GSTP) expression. The combined treatment of rituximab and artesunate reversed GSTP down-regulation (Fig. 7, lower panels). 

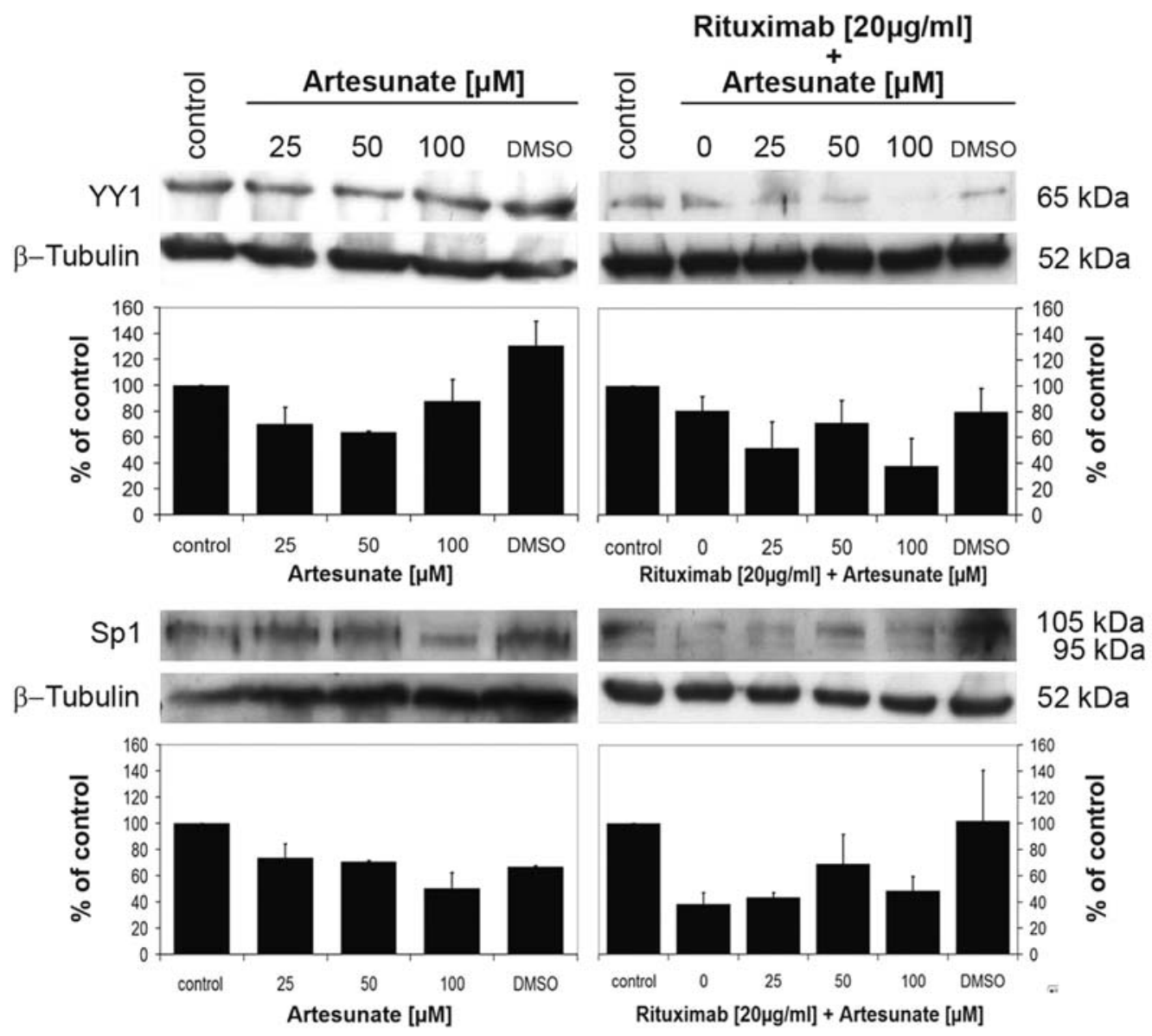

Figure 6. Inhibition of transcription factor expression by rituximab and artesunate. Ramos cells were left untreated or treated with artesunate (25-100 $\mu \mathrm{M})$, rituximab $(20 \mu \mathrm{g} / \mathrm{ml})$ or combinations of both agents. Upper panels show the results for YY1, lower panels for Sp1.

\section{Discussion}

In the present investigation, we found that rituximab potentiated the cytotoxic effect of artesunate on Ramos cells. While rituximab alone is minimally cytotoxic, rituximab increased the cytotoxicity to artesunate. This implies that rituximab may affect molecular mechanisms relevant for the action of artesunate. In previous studies, it has been shown that rituximab modulates the cytotoxicity of established anticancer drugs such as cisplatin or paclitaxel by induction of the mitochondrial pathway of apoptosis and inhibition of the p38 MAPK signal transduction pathway $(6,32)$. The synergistic effect might be explained by an interaction of both agents at the level of apoptosis or upstream of it. We found that artesunate induced apoptosis, induced Fas/CD95 expression and resulted in a breakdown of mitochondrial membrane potential. This argues for the involvement of both the receptor-driven extrinsic and the mitochondrial intrinsic routes of apoptosis. Rituximab increased Fas/CD95 expression and decreased mitochondrial membrane potential ultimately leading to increased rates of apoptosis. To the best of our knowledge, the substantial increase of Fas/CD95 expression by artesunate in malignant $\mathrm{B}$ cells is reported here for the first time.

Upstream regulators of apoptotic processes are transcription factors, which control the expression of apoptosis- regulating genes. In the present investigation, we focused on YY1 and Sp1 both of which have been described being involved in apoptosis regulation (33-35). It has previously been shown that rituximab affects the expression and activity of transcription factors such as YY1, which regulate key molecules of apoptosis, i.e. Fas/CD95 $(11,36)$. Recently, an inhibitory effect of YY1 has been described towards the death receptor DR5 (37). Thereby, the response of nonHodgkin's lymphoma cells to cisplatin or paclitaxel is improved. The rituximab induced down-regulation of the transcription factors, YY1 and Sp1, contribute to the upregulation of Fas/CD95, which increases the susceptibility of tumor cells to anticancer drug induced apoptosis. This has previously been shown for cisplatin, and this may also be true for artesunate as shown in the present investigation. We found that YY1 and also Sp1 were down-regulated and Fas/CD95 was up-regulated by rituximab and artesunate indicating that this mechanism is also relevant for artesunate. This finding is consistent with recent results of other authors showing that rituximab induces apoptosis by involvement of the Fas/CD95 pathway (38).

In addition to the extrinsic, receptor-driven pathway of apoptosis, we previously found that reactive oxygen species (ROS) and radical molecules play a role in leukemia cells (39-41). This points to the intrinsic, mitochondrial mode of apoptotic death. In the present study, we found that this is 


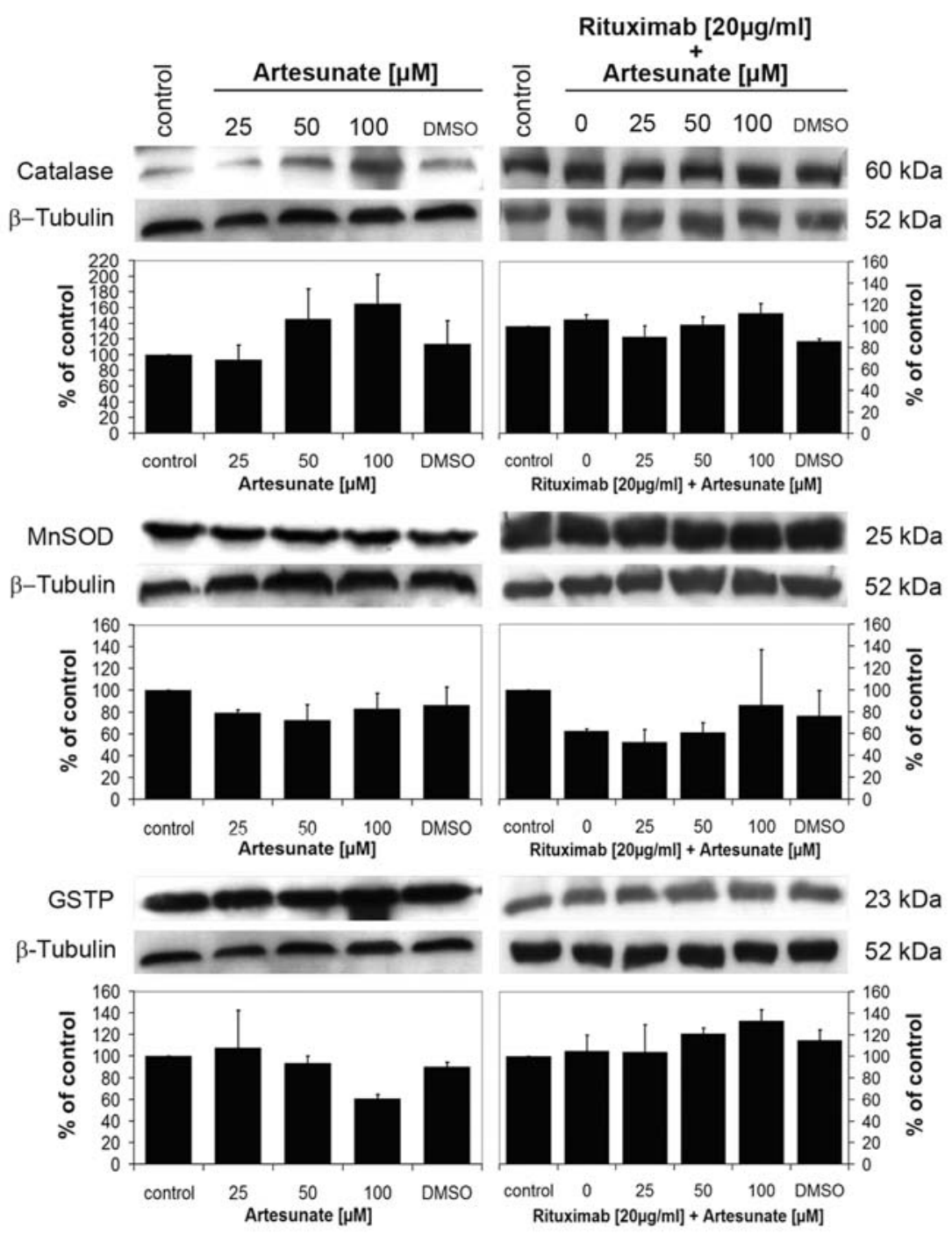

Figure 7. Effect of rituximab and artesunate on antioxidant proteins. Ramos cells were left untreated or treated with artesunate (25-100 $\mu \mathrm{M})$, rituximab (20 $\mu \mathrm{g} / \mathrm{ml})$ or combinations of both agents. Upper panels show the results for catalase (CAT), middle panels for manganese-dependent superoxide dismutase (MnSOD), and lower panels for glutathione S-transferase- $\pi$ (GSTP).

also true for Ramos cells, and that oxidative stress might play a role for the synergism between artesunate and rituximab. In this respect, artesunate is different from cisplatin, which does not form ROS in non-Hodgkin's lymphoma cells (6). In other cell systems, cisplatin has been described to cause ROS generation and mitochondrial oxidative stress (42). The major mode of action of cisplatin is adduct formation with DNA (cisplatin). As antioxidant stress genes play a role for artesunate's activity in cancer cells $(39,43)$, we investigated the role of rituximab on antioxidant genes. We found that rituximab enhanced artesunate-induced ROS formation. Furthermore, rituximab affected the expression of antioxidant genes. The antibody decreased artesunate-induced upregulation of catalase expression and increased artesunateinduced down-regulation of GSTP expression. MnSOD expression was not changed by artesunate, whereas the addition of rituximab led to a slight decrease of MnSOD protein levels. The changes of antioxidant proteins can be interpreted as defense of tumor cells against artesunateinduced ROS. Rituximab reversed these effects and, hence, reduced the detoxification capacity of Ramos cells. This explains at least in part the synergy of rituximab and

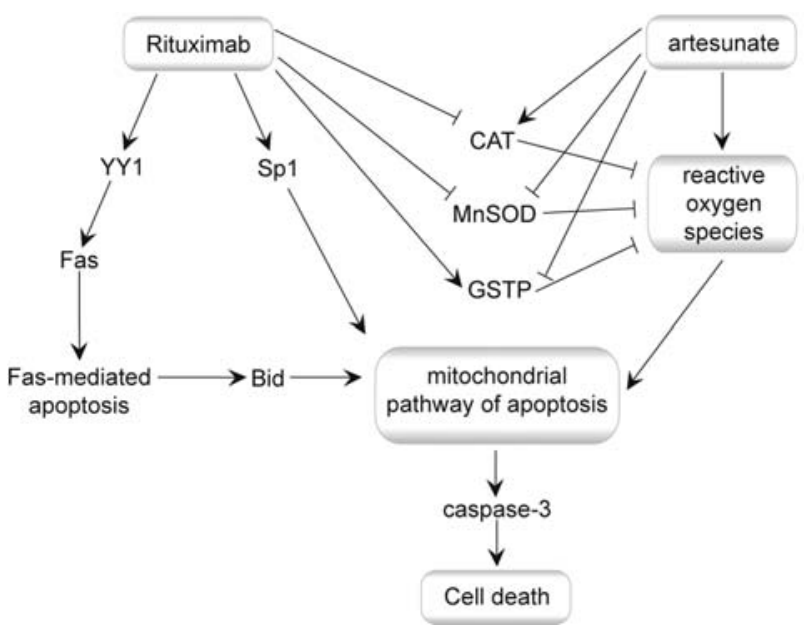

Figure 8. Proposed model of rituximab mediated sensitization of Ramos cells towards artesunate. Rituximab sensitizes Ramos cells for artesunate by increasing apoptosis, Fas/CD95 expression, and breakdown of mitochondrial membrane potential. The rituximab induced down-regulation of YY1 and Sp1 can explain up-regulation of Fas/CD95 and, hence, increased apoptosis. On the other hand, rituximab reversed artesunate-induced changes in the expression of antioxidant genes, thereby preventing detoxification of artesunateinduced ROS. 
artesunate. The effects of rituximab on antioxidant genes represent a novel mechanism of rituximab for chemosensitization.

Interestingly, the promoters of MnSOD, CAT and GSTP genes contain binding sequences for both transcription factors (43-49). It is, therefore, possible that rituximab sensitize Ramos cells to artesunate by YY1- and Sp1mediated modulation of expression of antioxidant genes. This hypothesis merits further exploration in the future.

In conclusion, rituximab sensitizes Ramos cells for artesunate by increasing apoptosis, Fas/CD95 expression, and breakdown of mitochondrial membrane potential. The rituximab-induced down-regulation of YY1 and Sp1 can explain up-regulation of Fas/CD95 and, hence, increased apoptosis. On the other hand, rituximab reversed artesunateinduced changes in the expression of antioxidant genes (Fig. 8), thereby preventing detoxification of artesunateinduced ROS.

\section{References}

1. Jemal A, Siegel R, Ward E, Murray T, Xu J and Thun MJ: Cancer statistics, 2007. CA Cancer J Clin 57: 43-66, 2007.

2. Reff ME, Carner K, Chambers KS, Chinn PC, Leonhard JE, Raab R, Newman RA, Hanna N and Anderson DR: Depletion of $\mathrm{B}$ cells in vivo by a chimeric mouse human monoclonal antibody to CD20. Blood 83: 435-445, 1994.

3. Grillo-Lopez AJ, White CA, Varns C, Shen D, Wei A, McClure A and Dallaire BK: Overview of the clinical development of rituximab: first monoclonal antibody approved for the treatment of lymphoma. Semin Oncol 26: 66-73, 1999.

4. Hennessy BT, Hanrahan EO and Daly PA: Non-Hodgkin lymphoma: an update. Lancet Oncol 5: 341-352, 2004.

5. Demidem A, Lam T, Alas S, Hariharan K, Hanna N and Bonavida B: Chimeric anti-CD20 (IDEC-C2B8) monoclonal antibody sensitises a B cell lymphoma cell line to cell killing by cytotoxic drugs. Cancer Biother Radiopharmaceut 12: 177-186, 1997.

6. Alas S, Ng C-P and Bonavida B: Rituximab modifies the cisplatin-mitochondrial signalling pathway, resulting in apoptosis in cisplatin-resistant Non-Hodgkin's lymphoma. Clin Cancer Res 8: 836-845, 2002.

7. Vega MI, Huerta-Yepaz S, Garban H, Jazirehi A, Emmanouilides C and Bonavida B: Rituximab inhibits p38 activity in 2F7 B NHL and decreases IL-10 transcription: pivotal role of p38 MAPK in drug resistance. Oncogene 23: 3530-3540, 2004.

8. Van der Kolk LE, Evers LM, Omene C, Lens SMA, Lederman S, van Lier RAW, van Oers MHJ and Eldering E: CD20-induced B cell death can bypass mitochondria and caspase activation. Leukemia 16: 1735-1744, 2002.

9. Jazirehi AR and Bonavida B: Cellular and molecular signal transduction pathways modulated by Rituximab (rituxan, antiCD20m Ab) in non-Hodgkin's lymphoma: implications in chemosensitization and therapeutic intervention. Oncogene 24: 2121-2142, 2005.

10. Vega MI, Huerta-Yepez S, Jazirehi AR, Garban H and Bonavida B: Rituximab (chimeric anti-CD20) sensitizes B-NHL cell lines to Fas-induced apoptosis. Oncogene 8: 8114-8127, 2005.

11. Vega MI, Jazirehi AR, Huerta-Yepez S and Bonavida B: Rituximab-induced inhibition of YY1 and Bcl-xL expression in Ramos non-Hodgkin's lymphoma cell line via inhibition of NF-kappa B activity: role of YY1 and Bcl-xL in Fas resistance and chemoresistance, respectively. J Immunol 175: 2174-2183, 2005.

12. Efferth T, Rücker G, Falkenberg M, Manns D, Olbrich A, Fabry U and Osieka R: Detection of apoptosis in KG-1a leukemic cells treated with investigational drugs. Arzneimittelforschung 46: 196-200, 1996.

13. Efferth T, Dunstan H, Sauerbrey A, Miyachi H and Chitambar CR: The anti-malarial artesunate is also active against cancer. Int Oncol 18: 767-773, 2001.
14. Efferth T: Mechanistic perspectives for 1,2,4-trioxanes in anticancer therapy. Drug Resist Update 8: 85-97, 2005.

15. Efferth T: Molecular pharmacology and pharmacogenomics of artemisinin and its derivatives in cancer cells. Curr Drug Targets 7: 407-421, 2006.

16. Efferth T: Willmar Schwabe Award 2006: antiplasmodial and antitumor activity of artemisinin - from bench to bedside. Planta Med 73: 299-309, 2007.

17. Kelter G, Steinbach D, Konkimalla VB, Tahara T, Taketani S, Fiebig $\mathrm{HH}$ and Efferth T: Role of transferrin receptor and the $\mathrm{ABC}$ transporters $\mathrm{ABCB} 6$ and $\mathrm{ABCB} 7$ for resistance and differentiation of tumor cells towards artesunate. PLoS ONE 2: e798, 2007.

18. Efferth T, Olbrich A and Bauer R: mRNA expression profiles for the response of human tumor cell lines to the antimalarial drugs artesunate, arteether and artemether. Biochem Pharmacol 64: $617-623,2002$.

19. Efferth T, Sauerbrey A, Olbrich A, Gebhart E, Rauch P, Weber HO, Hengstler JG, Halatsch ME, Volm M, Tew KD, Ross DD and Funk JO: Molecular modes of action of artesunate in tumor cell lines. Mol Pharmacol 64: 382-394, 2003.

20. Anfosso L, Efferth T, Albini A and Pfeffer U: Microarray expression profiles of angiogenesis-related genes predict tumor cell response to artemisinins. Pharmacogenomics J 6: 269-278, 2006.

21. Efferth T, Ramirez T, Gebhart E and Halatsch ME: Combination treatment of glioblastoma multiforme cell lines with the anti-malarial artesunate and the epidermal growth factor receptor tyrosine kinase inhibitor OSI-774. Biochem Pharmacol 67: 1689-1700, 2004.

22. Efferth T, Davey M, Olbrich A, Rücker G, Gebhart E and Davey R: Activity of drugs from traditional Chinese medicine toward sensitive and MDR1- or MRP1-overexpressing multidrug-resistant human CCRF-CEM leukemia cells. Blood Cells Mol Dis 28: 160-168, 2002.

23. Dell'Eva R, Pfeffer U, Vené R, Anfosso L, Forlani A, Albini A and Efferth T: Inhibition of angiogenesis in vivo and growth of Kaposi's sarcoma xenograft tumors by the anti-malarial artesunate. Biochem Pharmacol 68: 2359-2366, 2004.

24. Berger TG, Dieckmann D, Efferth T, Schultz ES, Funk JO, Baur A and Schuler G: Artesunate in the treatment of metastatic uveal melanoma - first experiences. Oncol Rep 14: 1599-1603, 2005.

25. Alas S and Bonavida B: Rituximab inactivates signal transducer and activation of transcription 3 (STAT3) activity in B-NonHodgkin's lymphoma through inhibition of the interleukin 10 autocrine/paracrine loop and results in down-regulation of bcl-2 and sensitisation to cytotoxic drugs. Cancer Res 61: 5137-5144, 2001.

26. Alas S, Emmanouilides C and Bonavida B: Inhibition of interleukin 10 by rituximab results in down-regulation of bcl-2 and sensitisation of B-cell Non-Hodgkin's lymphoma to apoptosis. Clin Cancer Res 7: 709-723, 2001.

27. DeNardo GL, Tobin E, Chan K, Bradt BM and DeNardo SJ: Direct antilymphoma effects on human lymphoma cells of monotherapy and combination therapy with CD20 and HLA-DR antibodies and ${ }_{90}$ Y-labeled HLA-DR antibodies. Clin Cancer Res 11 (Suppl. 19): S7075-S7079, 2005.

28. Nicoletti I, Migliorati G, Pagliacci MC and Ricardi C: A rapid and simple method for measuring thymocyte apoptosis by propidium iodide staining and flow cytometry. J Immunol Methods 139: 271-279, 1991.

29. Friesen C, Fulda S and Debatin KM: Cytotoxic drugs and the CD95 pathway. Leukemia 13: 1854-1858, 1999.

30. Pelicano H, Carney D and Huang P: ROS stress in cancer cells and therapeutic implications. Drug Resist Update 7: 97-110, 2004.

31. Garban HJ and Bonavida B: Nitric oxide disrupts $\mathrm{H}_{2} \mathrm{O}_{2}$ dependent activation of nuclear factor kappa $\mathrm{B}$. Role in sensitization of human tumor cells to tumor necrosis factor-alphainduced cytotoxicity. J Biol Chem 276: 8918-8923, 2001.

32. Jazirehi AR, Gan XH, De Vos S, Emmanouilides C and Bonavida B: Rituximab (anti-CD20) selectively modifies Bcl-xL and apoptosis protease activating dactor-1 (Apaf-1) expression and sensitizes human non-Hodgkin's lymphoma B cell lines to paclitaxel-induced apoptosis. Mol Cancer Ther 2: 1183-1193, 2003.

33. Utz PJ and Anderson P: Life and death decisions: regulation of apoptosis by proteolysis of signaling molecules. Cell Death Differ 7: 589-602, 2000 . 
34. Black AR, Black JD and Azizkhan-Clifford J: Sp1 and krüppellike factor family of transcription factors in cell growth regulation and cancer. J Cell Physiol 188: 143-160, 2001.

35. Lee JY, Huerta-Yepez S, Vega M, Baritaki S, Spandidos DA and Bonavida B: The NO TRAIL to YES TRAIL in cancer therapy (Review). Int J Oncol 31: 685-691, 2007.

36. Chan H, Bartos DP and Owen-Schaub LB: Activation-dependent transcriptional regulation of the human fas promoter requires NF-kB p50-p65 recruitment. Mol Cell Biol 19: 2098-2108, 1999.

37. Baritaki S, Huerta-Yepez S, Sakai T, Spandidos DA and Bonavida B: Chemotherapeutic drugs sensitize cancer cells to TRAIL-mediated apoptosis: up-regulation of DR5 and inhibition of Yin Yang 1. Mol Cancer Ther 6: 1387-1399, 2007.

38. Stel AJ, Ten Cate B, Jacobs S, Kok JW, Spierings DC, Dondorff M, Helfrich W, Kluin-Nelemans HC, De Leij LF Withoff $\mathrm{S}$ and Kroesen $\mathrm{BJ}$ : Fas receptor clustering and involvement of the death receptor pathway in rituximabmediated apoptosis with concomitant sensitization of lymphoma $\mathrm{B}$ cells to fas-induced apoptosis. J Immunol 178: 2287-2295, 2007.

39. Efferth T, Briehl MM and Tome ME: Role of antioxidant genes for the activity of artesunate against tumor cells. Int J Oncol 23 : 1231-1235, 2003.

40. Efferth T, Benakis A, Romero MR, Tomicic M, Rauh R, Steinbach D, Häfer R, Stamminger T, Oesch F, Kaina B and Marschall M: Enhancement of cytotoxicity of artemisinins toward cancer cells by ferrous iron. Free Radic Biol Med 37: 998-1009, 2004

41. Efferth T, Giaisi M, Merling A, Krammer PH and Li-Weber M: Artesunate induces ROS-mediated apoptosis in Doxorubicinresistant T leukemia cells. PLoS ONE 2: e693, 2007.
42. Martins NM, Santos NA, Curti C, Bianchi ML and Santos AC: Cisplatin induces mitochondrial oxidative stress with resultant energetic metabolism impairment, membrane rigidification and apoptosis in rat liver. J Appl Toxicol 28: 337-344, 2008.

43. Efferth T and Volm M: Glutathione-related enzymes contribute to resistance of tumor cells and low toxicity in normal organs to artesunate. In Vivo 19: 225-232, 2005.

44. Morrow CS, Cowan KH and Goldsmith ME: Structure of the human genomic glutathione S-transferase-pi gene. Gene 75: 3-11, 1989.

45. Wan XS, Devalaraja MN and St. Clair DK: Molecular structure and organization of the human manganese superoxide dismutase gene. DNA Cell Biol 13: 1127-1136, 1994

46. Van Remmen H, Williams MD, Yang H, Walter CA and Richardson A: Analysis of the transcriptional activity of the 5'flanking region of the rat catalase gene in transiently transfected cells and in transgenic mice. J Cell Physiol 174: 18-26, 1998.

47. Yeh CC, Wan XS and St. Clair DK: Transcriptional regulation of the 5' proximal promoter of the human manganese superoxide dismutase gene. DNA Cell Biol 17: 921-930, 1998.

48. Nenoi M, Ichimura S, Mita K, Yukawa O and Cartwright IL: Regulation of the catalase gene promoter by Sp1, CCAATrecognizing factors, and a WT1/Egr-related factor in hydrogen peroxide-resistant HP100 cells. Cancer Res 61: 5885-5894, 2001.

49. Xu Y, Porntadavity S and St. Clair DK: Transcriptional regulation of the human manganese superoxide dismutase gene: the role of specificity protein 1 (Sp1) and activating protein-2 (AP-2). Biochem J 362: 401-412, 2002. 